\title{
Impact of Personalized Social Media Advertising on Online Impulse Buying Behavior
}

\author{
Huzaifa Aslam $\mathbb{D} \mathbb{1}^{1}$, Muhammad Rashid ${ }^{\mathbb{D}}{ }^{2}$, Nouman Chaudhry ${ }^{\mathbb{D}}{ }^{3}$ \\ Department of Business Studies, Pakistan Institute of Development Economics, Islamabad, Pakistan. ${ }^{1}$ \\ Faculty of Management Sciences, International Islamic University, Islamabad, Pakistan. ${ }^{2}$ \\ University of Surrey, Guildford, England ${ }^{3}$
}

\section{ABSTRACT}

Personalization is used for marketing on social media by marketers and advertisers. So there is a great need to explore this phenomenon of personalization and online impulse buying behavior. This study examines the impact of personalized advertisement and its effects on online impulse buying behavior. This study is significant for online retailers and marketers. In this study, we developed a conceptual model. We then tested it while using different factors to know the power and impact of personalized advertisement on online impulse buying behavior through social media. We see perceived novelty and perceived relevance and online payment facility as mediators between personalized advertisement and online impulse buying behavior and privacy concerns as a moderator between payment facility and online impulse buying behavior. Developed a survey and filled it with 250 participants, then performed an analysis of correlation and regression; ten of the hypotheses of this study are supported by the finding of the results. And at the last chapter discussed the results and practical implications, and conclusion of the study.

\ Corresponding author: huzaifaaslam003@gmail.com
ARTICLE INFO

Received: May 25, 2021

Revised: July 8, 2021

Revised: August 11, 2021

Accepted: August 23, 2021

Published: September 6, 2021

\section{Keywords:}

Personalized Advertisement, Online Impulse Buying,

Perceived Relevance and

Novelty, Payment Facility, Privacy Concerns, Social Media

(cc) BY (C) 2021 The Author(s)

\section{Introduction}

Online Impulse buying is unplanned and immediate buying behavior that takes place either in Online stores or on Social Media, or on different E-commerce websites to fulfill the specific needs or wants of a buyer or a consumer (Leong, Jaafar, \& Ainin, 2018; Li, 2009). This impulse buying factor seems more in the young generation from 19 to 39 years old; the tendency of impulse buying is more in this age category. They see and buy immediately without any pre-shopping plans(Ouellette \& Wood, 1998). After 39 years, this thing starts decreasing because these people are not trending or fashion-conscious and have more control over their behavior than young ones. Young ones are more interested in new things, and they mostly follow fashion and trends. That factor makes them more interested in online impulse buying behavior (Bellenger, Robertson, \& Hirschman, 1978; Rawlings, Boldero, Wiseman, \& differences, 1995). 
Industry research and impulse buying literature indicated that buying impulse consists of $60 \%$ of all purchases (Amos, Holmes, \& Keneson, 2014). That fact suggests the importance of buying impulse in today 's business world. Another study indicates that impulse buying accounts for $40 \%$ of all online expenditure (Verhagen \& van Dolen, 2011). The dominion of online buying impulse (Corts, Wells, Signorelli, Hunter, \& Snyder, 2011) can be the character of several aspects just as they easily approach to services and the products, the quality of the website and layout and cues related to virtual and online payment facility (Floh, Madlberger, \& Applications, 2013; Jeffrey \& Hodge, 2007; Wells, Parboteeah, \& Valacich, 2011).

Nowadays, websites are new shopping channels and can be considered another choice for customers to perform impulse buying (Phau, Lo, \& Journal, 2004a). Online retail sales have a very bright future. It is foreseen that online sales will elucidate for 15 to 20\% of all retail and remarket sales in the US by 2010 (Economis, 2000). One of the most famous and common game plans for encouraging buying impulse is personalization. There is plenty of research done in the context of impulse buying behavior in shopping malls and stores. Still, there is minimal research that is done on online impulse buying behavior. Because of the previous and preceding literature on personalization, e-commerce, and advertising in this study, we presented a model based on a conceptual framework. That model explains the impact of personalization and how it influences consumers and customers to buy impulse online.

\section{Literature Review}

\section{Perceived Personalized Advertisement}

The definition of personalization is "It is processes that adopt marketing mix to an individual customer base, and the use of market information that is available about the customer and produces the individualized advertisements" (Montgomery \& Smith, 2009). Explicitly, in the setting of the web, database, and internet, it associates to the "company collected individual information and customer web experiences through cookies" (Allen, Yaeckel, \& Kania, 1998). The existence and the history of personalization were much older than the internet. The old studies and discussions revolve around the targeting and the segmentation (Petrison, Blattberg, \& Wang, 1997) of the customers, and the first simple example of personalization is to call the customers by their names while dealing with them in the mailing and the surveys (Cox III, Anderson Jr, \& Fulcher, 1974).

With the growth of social media applications, personalization also grows, like a recommendation of products on social media and websites of E-commerce. Personalized advertisements on social media are the advertisement message that appears on social media, and that message has some aspects of an individual customer (De Keyzer, Dens, \& De Pelsmacker, 2015; Tran, 2017). E-retailers and E-commerce companies created their pages on social media; they collected information regarding the people interested in their products and services (Koch \& Benlian, 2015; Ries, 2011).

\section{Online Impulse Buying Behavior}

Buying impulse is a unique and common feature among consumers. Companies and retailers now judge the importance of this phenomenon, called impulse buying behavior. Now retailers and companies are focusing on the in-store promotion, packaging of their products, and the layout of their stores. And they are trying to attract more consumers and customers towards their products, so they buy more impulsively (Dholakia, 2000). With time, innovations are made like the internet and computers, which made impulse buying easier. Telemarketing and 24/7 retailing through the internet are the future of companies and retailers (Rook, 1987).

Shopping through the internet and websites is a straightforward, convenient, and comfortable way of shopping (Szymanski \& Hise, 2000). Compared to the traditional market shopping experience, there is not the hustle and bustle of customers and there is no closing time or break times in online shopping. E-retailers and web stores are open 24/7, 365 days of the whole year (Lee, Chen, \& Fan, 2006). Hence, the consumers can 
browse the product at any time of day or night. And the different e-retailers are available on the internet, it's a matter of few minutes to locate the retailers, find the product, make a comparison of the product through evaluation of their price or others feature, and to finally select and buy the product at the ease of sitting at the homes (Madhavaram \& Laverie, 2004). Ozdemir and Akcay (2019) found a positive relationship between impulse buying and the ease of buying and shopping.

Impulse buying behavior is a state of mind where an individual makes a sudden and immediate buying decision to buy a product (Weun, Jones, \& Beatty, 1998). An impulse purchase creates a hasty decision to buy a specific product to fulfill a particular need or want, without pre-planning or pre-shopping intention (Beatty \& Ferrell, 1998). In other terms, Impulse buying is a concept that urges a person to feel a sudden desire to buy a specific product (de Kervenoael, Aykac, \& Palmer, 2009). Lim, Yazdanifard, and Research (2015) Found that many attributes can utter the idea of buying impulse. The 1st feature is buying impulse is usually unplanned and instant. 2nd feature is there is an external stimulus that is the cause of impulse buying behavior. 3rd the nature of buying impulse is prompt and short or no attention is given to exploration of information and to the alternative evaluation. Impulse buying was initially defined by the studies of Coley (2002) where author described that impulse buying is unplanned purchase behavior that is opposite to the shopping list that is made by the buyer. For example, if a buyer writes down the products he will buy when he visits the retail store and buys some more products not included in the shopping list earlier, unplanned or sudden shopping is called impulse purchase. In agreement with Stern (1962), there are four types of buying impulse behavior the 1 st one is pure impulse buying, 2nd one is reminder impulse buying behavior, 3rd one is suggestive impulse buying behavior, and the last one is planned impulse buying behavior.

According to Stern's four classifications of impulse buying behavior, we see online impulse buying behavior. Even nowadays, most of the studies on impulse buying use that four type classification and these classifications are tremendously crucial in buying impulse (Beatty \& Ferrell, 1998; Rook, 1987). The first scenario is that a person randomly sees the ad for shoes on social media and then decides to buy those shoes; that would be considered a pure impulse buying behavior. The second scenario is a lady sees a picture of lipstick on an ad on social media, and suddenly she thinks that she is running out of that product. She immediately purchases it, which is called reminder impulse buying behavior. 3rd example, a person sees the recommendation ad of a new detergent with the fragrance of jasmine on social media. So the person buys that detergent which is called lewd impulsive buying behavior. The last type of impulse buying occurs when a man is shopping online and has a list of things that he will buy online. Still, at the website, he sees the picture of the product available at a significant discount, so the man buys that discounted product against the effects written on the list. That is labeled as planned buying impulse behavior.

\section{Perceived Novelty}

Now online retailers and the seller adopt the novel strategies to come out from traditional ad clutter, customers encounter daily to that traditional ad clutter. So the E-retailers use new techniques and strategies to break that old ad clutter and come out with new and unique ads. Now retailers use location-based, personalized, and mobile social media advertising to reach out to customers in a novel and advanced way (Ketelaar et al., 2017; Unni \& Harmon, 2007; Wu, 2016; Xu, Oh, \& Teo, 2009). Novelty perception and relevance in ads personalization are considered an essential aspect in the paradigm of the ads communication (Sriram Kalyanaraman \& S Shyam Sundar, 2006). In simple words, we can say that when people encountered the personalized messages on media, they respond positively because of the innovativeness and novelty of the message, even they are already intimate and familiar with the content or character of the message (Carpenter, Glazer, \& Nakamoto, 1994; Sriram Kalyanaraman \& S Shyam Sundar, 2006).

The novelty in the personalized advertisements is one of the huge factors that recognize the consumers' need and want in advance, offer them different products and services, and encourage them to buy impulsively 
(Sharma, Sivakumaran, \& Marshall, 2010). Hausman (2000) stated in the study that there is a positive relationship between novelty as a benchmark of epicurean desire and buying impulse.

\section{Perceived Relevance}

Firstly, to learn about the profile of the customers, their interests, needs, browsing history, and online activities, create advertisements for them according to their profiles, which is called relevance of the personalized ad on social media. Because of the personalized advertisement and relevance, customers feel that advertising is for them, their self-relevance increased towards the advertisement. The personalized advertisement meets their customers' vast or little interest (Kreuter \& Wray, 2003; Petty, Barden, \& Wheeler, 2009). Personal relevance is a cognitive process that is stimulated by external sources in which the public judges how much the source is valuable for them and how it fulfills their needs and wants (Celsi \& Olson, 1988; Xia \& Bechwati, 2008). According to the prior studies, lack of relevance is one of the main reasons behind the customers' ignorance of ads on social media (Kelly, Kerr, \& Drennan, 2010).

\section{Online Payment Facility}

People don't want to retain currency in a tangible form with them, they put that amount in their bank accounts and only keep their financial cards with them for transactional purpose, Financial mobile accounts and cards are facilitating public for their financial transactions and making their shopping experience much more accessible than past, products preferred cost decreases by the use of credit card. The use of credit cards makes it easy to get credit from the lender of the credit card (Ampuero \& Vila, 2006). The effects of financial card usage are found in the individual attitude and their demographics like their marital status, education, profession, age, and income level (Park \& Forney, 2004). Usage and the possession of the financial card increased the speed of spending, magnitude, and profitability (Feinberg, 1986). And lastly, increase the probability of impulse buying behavior (Roberts \& Jones, 2001). The use of financial cards increased day by day globally, and it decreased the need for an amount at hand day by day.

\section{Privacy Concerns}

We define privacy as the person's ability and right to control the terms and conditions used to get personal information and then the different use of that personal information at other platforms (Westin, 1967). The uses of online payment facilities like providing the credit/debit card number over the website to E-retailer for the completion of procedures of your online purchase. Online buyers sometimes trade-off to their privacy concerns. While performing the online impulse buying and using the online payment facility, their personal and confidential information like financial card numbers, ID cards numbers, passwords are required at that step by the E-retailer company (Sheng, Nah, \& Siau, 2008). A study survey by Antón, Earp, and Young (2010) mentions that when customers provide their confidential and secret information over the internet while doing online buying or other, their privacy concerns are increased. As the use of online buying increased day by day on social media, the privacy concerns over personal information increased day by day as well (Toch, Wang, \& Cranor, 2012). 


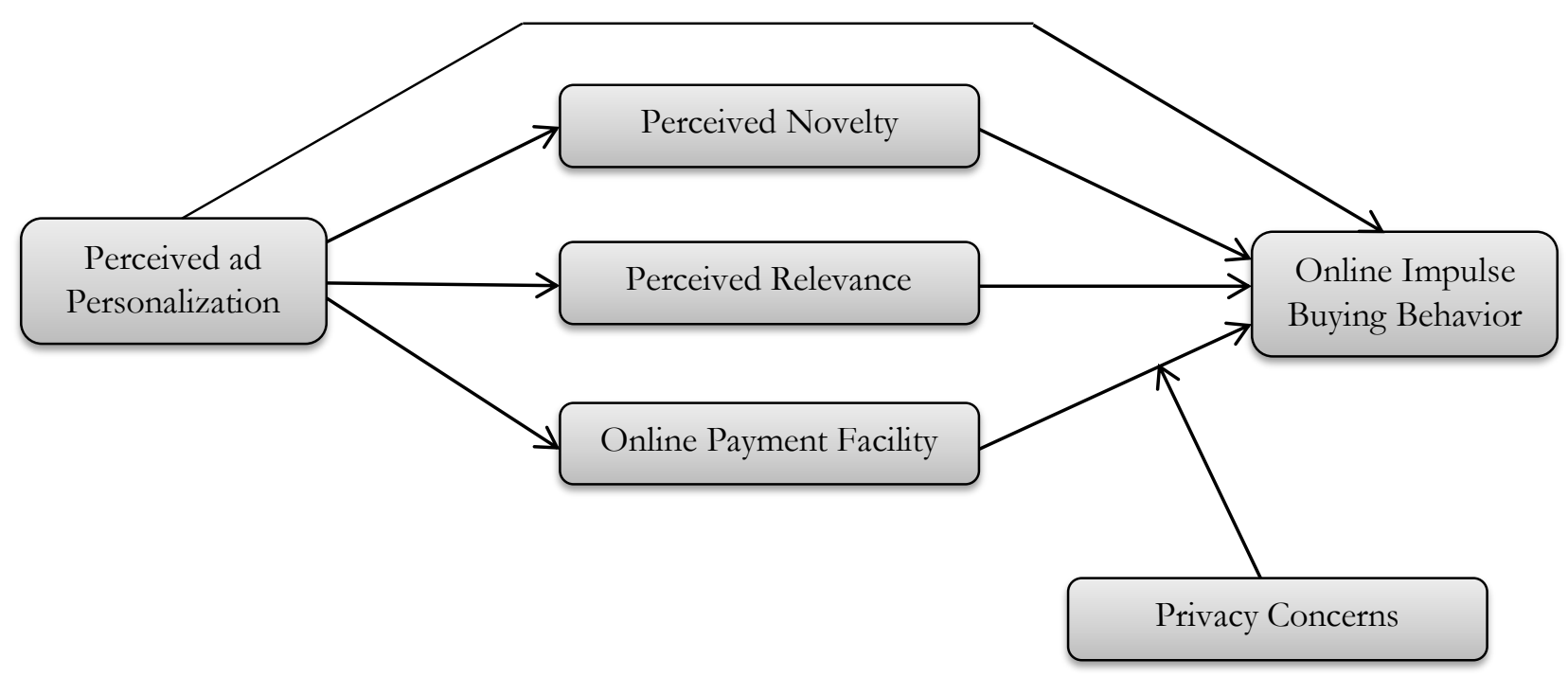

Figure 1 - Conceptual model

\section{Hypothesis Development:}

H1: Customer Perceived Advertisement Personalization has an encouraging and positive effect on their online impulse buying behavior.

H2: Customer-perceived Advertisement personalization on social media will positively associate with their perceived advertisement novelty.

H3: Perceived Novelty of customers' advertisement will firmly and positively associate with their online buying impulse behavior.

H4: Customer Perceived Advertisement Personalization positively affects their online buying impulse Behavior, and perceived novelty significantly mediates the relationship.

H5: Customer perceived advertisement personalization on social media will positively associate to their perceived advertisement relevance.

H6: Perceived Relevance of the customers regarding social media advertisement will favorably and positively associate with their online buying impulse behavior.

H7: Customer-perceived advertisement personalization will positively associate their online impulse buying behavior when perceived relevance is a mediator.

H8: Customer perceived advertisement personalization on social media will positively associate with their online payment facility. behavior.

H9: Online Payment Facility has a positive relationship with the customer 's online impulse buying

H10: Customers perceive advertising personalization positively influences their online impulse buying behavior when we see payment facility as a mediator between Perceived advertisement personalization and online impulse buying behavior.

H11: Customer Privacy concerns regarding online payment facilities will negatively influence their online buying impulse behavior. 


\section{Methodology}

This research is exploratory. We use quantitative surveys to collect data for this study. We developed a questionnaire on a google doc, distributed it online through social media sites and e-mails. We used perceived novelty, relevance, and payment facility as mediator variables between the independent variable of perceived advertisement personalization and the dependent variable of online impulse buying behavior. And lastly, we see privacy concerns as a moderator variable between the payment facility and the online impulse buying behavior.

\section{Population and Sample size}

The population of our study is the people who are engaged in online buying behavior. Most of the youth of our country are using the internet and social media, and they are more involved in online buying behavior. We target them to get to know the impact of personalization advertisements on their online impulse buying behavior. The sample size of our study is almost 250 participants. Two hundred and fifty participants fill the online questionnaire of Google Docs. The sample that we include in our research will be the youth of Pakistan. Because according to the industry reports, the students of colleges and universities were most active on social media. They have groups for mutual discussion, and they are more involved in online selling and buying (Dodoo, 2019). The Students from different universities across Pakistan, mainly from Rawalpindi, Faisalabad, and Islamabad, are participating in the survey. So we will use non-probability, convenience sampling techniques in this study for the collection of data.

\section{Data collection and analysis}

In our study, we collect primary data through a quantitative online survey questionnaire. So we developed the online questionnaire and filled it with the young population of Pakistan, who are involved in online buying behavior. We use SPSS for the analysis and finding of the results of this study.

\section{Results and Discussion}

\section{Reliability Analysis}

Cronbach's Alpha is a technique that is used to check the internal consistency between the measures. Cronbach's Alpha is poor if its value is less than 0.5; it's considered poor or unaccepted reliability. And if the value of Cronbach's Alpha is more than 0.6 so we consider it moderate reliable. If the value and worth of Cronbach alpha are more than 0.7 , then it's considered and pondered as a satisfactory value of reliability (Sekaran \& Bougie, 2003).

Table No 1: Reliability Analysis

\begin{tabular}{cccc}
\hline Serial Numbers & Variables of the study & Numbers of Items & Cronbach Alpha \\
\hline 1. & PPA & 5 & 0.816 \\
2. & OIBB & 7 & 0.866 \\
3. & PR & 2 & 0.702 \\
4. & PN & 2 & 0.702 \\
5. & PF & 5 & 0.766 \\
6. & PC & 4 & 0.786
\end{tabular}

PPA=Perceived Personalized Advertisement, $\mathrm{OIBB}=$ Online Impulse buying behavior, PR=Perceived Relevance, $\mathrm{PN}=$ Perceived Novelty, PF= Payment Facility, PC=Privacy Concerns.

Table 1 tells us about the hole variables of the study; the first variable, PPA, has five no of items and its reliability is 0.816 next variable OIBB has seven items, and its reliability is 0.866 , next two variables PN and 
PR, both have two items and their reliability value is 0.702 , Next variable PF has five items and 0.766 reliability. The last variable, PC, has four items and a 0.786 value of reliability.

\section{Demographic Statistics}

Demographically $75 \%$ of participants of this study were male, and $24.9 \%$ were female. Age-wise young people who are 18 to 25 years old, their participation was 59\%, 26 to 32 years old, their participation was $35 \%$. So Most of the youth who participated in this study and industry research said that college-aged students were mainly and regularly used social media and are more involved in online buying, so we target college and university students as the participants of this study. Qualification wise most participants were masters and graduates. Then past online buying experience, $36 \%$ of people have only one to two-time online buying experiences, $30 \%$ people have 9 to more than ten times of experience related to online buying.

\section{Descriptive Statistics}

Table 2 describes the mean and standard deviation of the variables, mean an average value of the data that one value represents the whole data set, and the standard deviation is how much the data is a deviation from the standard like the difference between the average of the data, low standard deviation means that the values are close to mean. High standard deviation means that values are scattered out over an extensive range. PPA has a mean of 3.7488 and a Standard Deviation of .88246, OIBB has a Standard Deviation of 1.35787 and a mean value of 3.9291. The following variable, PR has a mean of 4.4500 and Standard Deviation of 1.44876, PN has a mean of 4.6740 and Standard Deviation of 1.30827, PF has a mean of 4.6336 and Standard Deviation 1.27886, Last one PC has a mean of 5.4528 and Standard Deviation of 1.121141.

Table 2: Descriptive statistics

\begin{tabular}{lll}
\hline Variables & Mean & Standard Deviation \\
\hline PPA & 3.7488 & .88246 \\
OIBB & 3.9291 & 1.35787 \\
PR & 4.4500 & 1.44876 \\
PN & 4.6740 & 1.30827 \\
PF & 4.6336 & 1.27886 \\
PC & 5.4528 & 1.12114 \\
\hline
\end{tabular}

$\mathrm{PPA}=$ Perceived Personalized Advertisement, $\mathrm{OIBB}=$ Online Impulse buying behavior, $\mathrm{PR}=$ Perceived Relevance, $\mathrm{PN}=$ Perceived Novelty, PF= Payment Facility, PC=Privacy Concerns

Table 3: Correlation

\begin{tabular}{lllllll}
\hline Correlation & PPA & OIBB & PR & PN & PF & PC \\
\hline $\begin{array}{l}\text { Perceived } \\
\text { Personalized }\end{array}$ & 1 & & & & & \\
Advertisement & & & & & & \\
Online Impulse Buying & Behavior & $.416^{* *}$ & 1 & & & \\
Perceived Relevance & $.404^{* *}$ & $.681^{* *}$ & 1 & & & \\
Perceived Novelty & $.361^{* *}$ & $.515^{* *}$ & $.597^{* *}$ & 1 & & \\
Payment Facility & $.265^{* *}$ & $.432^{* *}$ & $.379^{* *}$ & $.360^{* *}$ & 1 & \\
Privacy Concerns & .090 & $.127^{*}$ & $.174^{* *}$ & $.176^{* *}$ & $.328^{* *}$ & 1 \\
\hline
\end{tabular}

[** correlation is significant at the 0.01 level (2-Tailed)]

[ ${ }^{*}$ Correlation is significant at the 0.05 level (2-Tailed)]

Table 3 shows us the correlation between the variables. Correlation shows us the relation between variables. The value of correlation is significant and remarkable at the value $(\mathrm{P}<0.01)$, then the relation shows 
$\left.{ }^{(* *}\right)$, and if the correlation value is remarkable at value $(\mathrm{P}<0.05)$, so the relation shows $\left(^{*}\right)$. OIBB and PPA have a positive significant and remarkable relationship $\left(\mathrm{P}<0.01, \mathrm{~B}=0.416^{* *}\right)$ with OIBB that supported that $\mathrm{H} 1$, So $2^{\text {nd }}$ hypothesis is accepted because $\left(\mathrm{P}<0.01, \mathrm{~B}=0.361^{* *}\right)$, So PPA has a significant positive relationship with PN. PN has a significant positive relation $\left(\mathrm{P}<0.01, \mathrm{~B}=0.515^{* *}\right)$ with $\mathrm{OIBB}$, supporting $\mathrm{H} 3$. PR has a positive significant $\left(\mathrm{P}<0.01, \mathrm{~B}=0.404^{* *}\right)$ relation with $\mathrm{PPA}$, so the $\mathrm{H} 5$ is accepted. $\mathrm{PR}$ has a positive $(\mathrm{P}<0.01, \mathrm{~B}$ $\left.=0.681^{* *}\right)$ relation with $\mathrm{OIBB}$, so $\mathrm{H} 6$ is accepted. PPA has a positive significant $\left(\mathrm{P}<0.01, \mathrm{~B}=0.265^{* *}\right)$ relation with PF that supports $\mathrm{H} 8$ of the study. PF has a positive significant $\left(\mathrm{P}<0.01, \mathrm{~B}=0.432^{* *}\right)$ impact with OIBB, so the 9 th hypothesis is accepted. $\mathrm{PC}$ has a positive significant $\left(\mathrm{P}<0.05, \mathrm{~B}=0.127^{*}\right)$ relation with OIBB, so the 11th hypothesis is rejected in the study.

\section{Regression Analysis}

This study explores the impact of personalized social media advertising on online impulse buying behavior, and we see perceived relevance, novelty, and online payment facility as a mediator. So now we see the relationship between IV and DV and mediators as well. And we see direct and indirect relationships between the different variables, and after that, we can see whether the hypothesis of this study is supported by regression analysis or not. Then we perform a regression analysis to check the impact of IV to DV of this study. We used a process method approach by Preacher (2008) to run the mediation and moderation analysis on this study. Hayes and Preacher developed seventy-four models; all the models are different, and those models efficiently fulfill the requirements of all research models approximately. I used version 3.4 of the process, model 4 for mediation, and model 1 for moderation.

\section{Mediation of Perceived Novelty, Perceived Relevance, and Payment Facility}

Table 4: (a) Direct Relationship,

\begin{tabular}{lllllll}
\hline Variables, & $\boldsymbol{\beta}$, & LLCI, & ULCI, & P, & S.E, & T, \\
\hline Direct Effect, IV to DV PPA To OIBB (H1) & 0.26 & 0.11 & 0.41 & 0.00 & 0.08 & 3.39 \\
IV to Mediators, & 0.53 & 0.36 & 0.71 & 0.00 & 0.09 & 6.09 \\
PPA to PN (H2) & & & & & & \\
PPA to PR (H5) & 0.66 & 0.48 & 0.85 & 0.00 & 0.10 & 6.96 \\
PPA to PF (H8) & 0.38 & 0.21 & 0.56 & 0.00 & 0.09 & 4.32 \\
Mediators to DV, & 0.44 & 0.32 & 0.55 & 0.00 & 0.05 & 7.50 \\
PN to OIBB (H3) & & & & & & \\
PR to OIBB (H6) & 0.57 & 0.48 & 0.67 & 0.00 & 0.06 & 12.30 \\
PF to OIBB (H9) & 0.37 & 0.25 & 0.48 & 0.00 & 0.06 & 6.20 \\
\hline
\end{tabular}

$\mathrm{PPA}=$ Perceived Personalized Advertisement, OIBB=Online Impulse buying behavior, PR=Perceived Relevance, $\mathrm{PN}=$ Perceived Novelty, PF= Payment Facility, PC=Privacy Concerns.

In Table 4(a), Firstly, we see the direct relation of IV (PPA) to DV (OIBB), which is a positive relationship, so the first hypothesis of the study is accepted. Then we see IV to Mediators relationship. Their beta values are $0.53,0.66$, and 0.38 , respectively, so hypotheses 2,5 , and 8 were supported according to the value that we see above in the table. We see the relationship between mediators to DV; the values are 0.44 , 0.57 , and 0.37 , respectively, so these values supported hypotheses no $\mathrm{H} 3, \mathrm{H} 6$, and $\mathrm{H} 9$. The significance values of all the outcomes were (0.00).

Bootstrap for the indirect effect of Perceived Personalized Advertisement to Online Impulse Buying behavior through mediators of Perceived Novelty, Perceived Relevance, and Payment Facility. 
Table 4(b) - Mediation

\begin{tabular}{lllll}
\hline $\begin{array}{l}\text { Indirect effect of IV to DV, } \\
\text { Through Mediation }\end{array}$ & B & Boot S.E & LLCI & ULCI \\
\hline PPA-PN-OIBB (H4) & 0.23 & 0.04 & 0.15 & 0.32 \\
PPA-PR-OIBB (H7) & 0.38 & 0.06 & 0.27 & 0.51 \\
PPA-PF-OIBB (H10) & 0.14 & 0.04 & 0.06 & 0.23
\end{tabular}

$\mathrm{PPA}=$ Perceived Personalized Advertisement, $\mathrm{OIBB}=$ Online Impulse buying behavior, $\mathrm{PR}=$ Perceived Relevance, $\mathrm{PN}=$ Perceived Novelty, PF= Payment Facility, PC=Privacy Concerns.

In this table of $4(\mathrm{~b})$, the indirect effect of $\mathrm{PPA}$ on $\mathrm{OIBB}$ through mediator $\mathrm{PN}$ is 0.23 , supporting hypothesis no 4 of the study. Beta value is the measure of how strongly one variable influences the other variable and beta value measured in standard deviation, like in hypothesis no four the beta value is 0.23 it indicates that if the change of standard deviation of 0.23 in the IV (PPA) will result in a change of value 0.23 in DV (OIBB) also. Then we see PR as a mediator between PPA and OIBB. The bate value is 0.38 that supports hypothesis no 7. And lastly, we see PF as a mediator, and that beta value is 0.14 also supports hypothesis no 10 . The confidence level for all confidence intervals in output is 95.00; the Number of bootstrap samples for percentile bootstrap confidence intervals is 1000. Upper-level confidence interval and lower level confidence values also mention in the table.

\section{Moderation Analysis}

Table 5 shows us the moderation analysis; we only have one moderator in this study; let's discuss the results below. We have Privacy concerns as a moderator among Payment facilities and online impulse Buying behavior. We develop hypothesis no 11 on privacy concerns that Privacy concerns negatively impact the relation of Payment facility and online impulse buying behavior. Privacy concerns show us the beta value of 0.55 as a moderator among Payment facility and the online impulse buying behavior, and it has a significant value of 0.07 that is greater than $(\mathrm{P}>0.05)$, So our hypothesis no 11 is not supported according to this table values and rejected.

Table 5: Model summary

\begin{tabular}{|c|c|c|c|c|c|c|}
\hline $\mathbf{R}$ & $\mathbf{R} 2$ & $\mathbf{F}$ & Dfl & & Df2 & $\mathbf{P}$ \\
\hline 0.44 & 0.20 & 20.20 & 3.00 & & 246.00 & 0.00 \\
\hline \multicolumn{7}{|c|}{ Path Confidence } \\
\hline & B & S.E & $T$ & $\mathbf{P}$ & LLCI & ULCI \\
\hline Constant & 4.48 & 1.65 & 2.72 & 0.01 & 1.24 & 7.72 \\
\hline PPA & -0.34 & 0.44 & -0.76 & 0.45 & -1.21 & 0.54 \\
\hline PC & -0.55 & 0.30 & -1.80 & 0.07 & -1.14 & 0.05 \\
\hline PPA*PC & 0.18 & 0.08 & 2.23 & 0.03 & 0.02 & 0.34 \\
\hline \multicolumn{7}{|c|}{ Interaction PPA*PC } \\
\hline & & & & Dfl, & Df2, & $\mathbf{P}$ \\
\hline PPA*PC, & & & & 1.0 & 346 & 0.19 \\
\hline
\end{tabular}

\section{Proposed Hypothesis Results}

\section{Hypothesis}

H1: Customer Perceived Advertisement Personalization has an encouraging and positive effect on their online impulse buying behavior.

H2: Customer-perceived Advertisement personalization on social media will positively associate with their perceived advertisement novelty.
Results

Supported

Supported 
H3: H3: Perceived Novelty of customers' advertisement will firmly and positively associate with their online buying impulse behavior.

Supported

H4: Customer Perceived Advertisement Personalization has a positive effect on their online buying Supported impulse Behavior and perceived novelty significantly mediate the relationship

H5: Customer perceived advertisement personalization on social media will positively associate to their perceived advertisement relevance.

H6: Perceived Relevance of the customers regarding social media advertisement will favorably and positively associate with their online buying impulse behavior.

H7: Customer-perceived advertisement personalization will positively associate their online impulse buying behavior when perceived relevance is a mediator.

H8: Customer perceived advertisement personalization on social media will positively associate with their online payment facility.

H9: Online Payment Facility has a positive relationship with the customer's online impulse buying behavior.

H10: Customers perceive advertising personalization positively influences their online impulse buying behavior when we see payment facility as a mediator between Perceived advertisement personalization and online impulse buying behavior.

H11: Customer Privacy concerns regarding online payment facilities will negatively influence their online impulse buying behavior.

Supported

Supported

Supported

Supported

Supported

Supported

Unsupported

\section{Conclusion}

The primary purpose and motive of the study were to check the impact of personalized advertisement on online impulse behavior buying. In today's business world, with the passage of time, online buying and selling have become famous around the globe. E-retailers and companies are trying to increase their sales through online impulse buying, increasing day by day. So there is a positive impact of perceived personalization advertisement on consumer online impulse buying behavior. So the sole purpose of the study is to find out that there is any influence of personalized advertising on social media on online impulse buying behavior.

Perceived personalization advertisement has a significant and remarkable impact on online impulse buying behavior. Previous research also indicates that personalized social media advertising positively impacts online impulse buying (de Kervenoael et al., 2009). Perceived relevance has a significant positive impact with perceived personalization of advertisement, so hypothesis no five was accepted, when the (stimuli or motive) advertisements are correlated to the self of the man (like the ads are related to the person who is watching this ad), then the chances of action (buying impulse) increases much (Phau, Lo, \& Journal, 2004b). Perceived relevance has positively associated with online impulse buying behavior that supports hypothesis no 6; if the advertising message is related to and matches with the customers self, then there are more chances that the online impulse buying will occur (Sriram Kalyanaraman \& S Shyam Sundar, 2006). And suppose we see the indirect relationship of Perceived personalized advertisement with online impulse buying behavior through perceived relevance that shows the beta value of 0.38 and supports hypothesis no 7 of the study. In that case, the Beta value measures how strongly one variable influences the other variable, and the beta is measured in standard deviation. The perceived novelty of advertisement has a much valuable for online impulse buyers. For Personalized advertising, our results of the data show that hypotheses no 5 and 6 were accepted, the novelty of the advertisement like mobile social media and location-based advertisement, geo-fencing that modern technologies have risen the modern ways of advertising for the markers and advertisers(Unni \& Harmon, 2007). Payment facility, online impulse buying behavior, and personalized advertisement positively support hypotheses no 8 and 9. In hypothesis no four, we see the indirect relationship of PPA to OIBB through the mediator of perceived novelty, and the data value supported that. And lastly, we see the indirect effect of PPA on OIBB through payment facilities. The results support our hypothesis no 10; according to previous studies, online payment facility increases the chances of online impulse buying behavior (Roberts \& Jones, 2001). 
We see privacy concerns as a moderator among payment facilities and the online impulse buying behavior, and we hypothesis that privacy concern hurts online impulse buying behavior; results show that our hypothesis no 11 was rejected because it has a significant value of 0.07 that is more than 0.05 , so our hypothesis no 11 was rejected. Pakistan is a non-documented economy, and almost $60 \%$ of the transactions are on a cash basis. And the use of credit or debit cards or other financial services is much lesser than the documented and developed economies. Previous studies said that up to $60 \%$ of the economy is informal. The tax net is very limited in Pakistan; more than 90\% of payments are through cash on delivery of the products that are bought online, only 24\% of the population have bank accounts(International Trade Administration, n.d.). Another justification is that according to the Asian development bank report year 2018, that report said that while online shopping, 95\% of Pakistanis use cash on delivery option to pay their payments(Saleem, 2019), so when most of the country's public use cash on delivery to pay their payments of online bought product, so the privacy concerns regarding online payment facility are not applicable here at Pakistan, lack of trust on online sellers is one of the main reason that why people don't use online payment and don't pay their payments instantly

\section{Practical Implications}

The study's practical implication is that this study is constructive for the companies (who are doing online selling) and for E-retails, online marketers, policymakers, and advertisers that personalized targeting and advertisement are tremendously important. Social media marketers and sellers should adopt and start doing personalized advertisements rather than general advertisements, and it is constructive for them and boosts boom their sales volume (Tran, 2017). The perceived relevance of the advertisements is significant, and advertisers need to send the advertising message relevant to the want and needs of the customers. Advertising novelty is vital to break the current clutter of the advertisement, modern and new advertising strategies, and technologies.

\section{Limitation and Future Direction}

This study sees Perceived Relevance, Novelty, and Payment facility as mediators between the Perceived Personalized Advertisement and online impulse buying behavior. Future and further research could see the other factors and motives that may influence online impulse buying behavior like the product category, selling website quality, sales, and promotions, etc.

Funding: This research received no external funding.

Conflicts of Interest: The authors declare no conflict of interest.

\section{References}

Allen, C., Yaeckel, B., \& Kania, D. (1998). Internet world guide to one-to-one web marketing: John Wiley \& Sons, Inc. Amos, C., Holmes, G. R., \& Keneson, W. C. (2014). A meta-analysis of consumer impulse buying. Journal of Retailing and Consumer Services, 21(2), 86-97.

Ampuero, O., \& Vila, N. (2006). Consumer perceptions of product packaging. Journal of Consumer Marketing, 23(2), 100-112.

Antón, A. I., Earp, J. B., \& Young, J. D. (2010). How internet users' privacy concerns have evolved since 2002. Journal of IEEE Security Privacy, 8(1), 21-27.

Beatty, S. E., \& Ferrell, M. E. (1998). Impulse buying: Modeling its precursors. Journal of Retailing, 74(2), 169191.

Bellenger, D. N., Robertson, D. H., \& Hirschman, E. C. (1978). Impulse buying varies by product. Journal of Advertising Research, 18(6), 15-18.

Carpenter, G. S., Glazer, R., \& Nakamoto, K. (1994). Meaningful brands from meaningless differentiation: The dependence on irrelevant attributes. Journal of Marketing Research, 31(3), 339-350. 
Celsi, R. L., \& Olson, J. C. (1988). The role of involvement in attention and comprehension processes. Journal of Consumer Research, 15(2), 210-224.

Coley, A. L. (2002). Affective and cognitive processes involved in impulse buying. Citeseer,

Corts, D., Wells, B., Signorelli, P., Hunter, L., \& Snyder, T. (2011). System and method for generating multimedia accompaniments to broadcast data. In. U.S. Patent No. 7,908,172. Washington, DC: U.S. Patent and Trademark Office: Google Patents.

Cox III, E. P., Anderson Jr, W. T., \& Fulcher, D. G. (1974). Reappraising mail survey response rates. Journal of Marketing Research, 11(4), 413-417.

de Kervenoael, R., Aykac, D. S. O., \& Palmer, M. (2009). Online social capital: Understanding e-impulse buying in practice. Journal of Retailing and Consumer Services, 16(4), 320-328.

De Keyzer, F., Dens, N., \& De Pelsmacker, P. (2015). Is this for me? How consumers respond to personalized advertising on social network sites. Journal of Interactive Advertising, 15(2), 124-134.

Dholakia, U. M. (2000). Temptation and resistance: An integrated model of consumption impulse formation and enactment. Psychology \& Marketing, 17(11), 955-982.

Dodoo, N. A. (2019). Exploring the anteceding impact of personalised social media advertising on online impulse buying tendency. Internet Marketing and Advertising, 13(1).

Economis. (2000). Shopping around the web. ???, 354 (No. 8159.).

Feinberg, R. A. J. (1986). Credit cards as spending facilitating stimuli: A conditioning interpretation. Journal of Consumer Research, 13(3), 348-356.

Floh, A., Madlberger, M. J. E. C. R., \& Applications. (2013). The role of atmospheric cues in online impulsebuying behavior. Electronic Commerce Research and Applications, 12(6), 425-439.

Hausman, A. J. (2000). A multi-method investigation of consumer motivations in impulse buying behavior. Journal of Consumer Marketing, 17(5), 403-426.

International Trade Administration. (n.d.). Retrieved from https://www.trade.gov/knowledgeproduct/pakistan-market-overview? section-nav $=3640$

Jeffrey, S. A., \& Hodge, R. J. E. C. R. (2007). Factors influencing impulse buying during an online purchase. Electronic Commerce Research, 7(3-4), 367-379.

Kalyanaraman, S., \& Sundar, S. S. (2006). The psychological appeal of personalized content in web portals: does customization affect attitudes and behavior? Journal of Communication, 56(1), 110-132.

Kalyanaraman, S., \& Sundar, S. S. (2006). The psychological appeal of personalized content in web portals: does customization affect attitudes and behavior? Journal of Communication, 56(1), 110-132.

Kelly, L., Kerr, G., \& Drennan, J. (2010). Avoidance of advertising in social networking sites: The teenage perspective. Journal of Interactive Advertising, 10(2), 16-27.

Ketelaar, P. E., Bernritter, S. F., van't Riet, J., Hühn, A. E., van Woudenberg, T. J., Müller, B. C., \& Janssen, L. J. (2017). Disentangling location-based advertising:The effects of location congruency and medium type on consumers' ad attention and brand choice. International Journal of Advertising, 36(2), 356-367.

Koch, O. F., \& Benlian, A. J. J. o. I. M. (2015). Promotional tactics for online viral marketing campaigns: how scarcity and personalization affect seed stage referrals. Journal of Interactive Marketing, 32, 37-52.

Kreuter, M. W., \& Wray, R. J. (2003). Tailored and targeted health communication: strategies for enhancing information relevance. journal of health behavior, 27(1), 227-232.

Lee, C.-S., Chen, Y. G., \& Fan, Y.-H. (2006). Structure and components of e-commerce business model. In Encyclopedia of E-Commerce, E-Government, and Mobile Commerce (pp. 1058-1063): IGI Global.

Leong, L.-Y., Jaafar, N. I., \& Ainin, S. (2018). The effects of Facebook browsing and usage intensity on impulse purchase in f-commerce. 78, 160-173.

Li, K., Lee. (2009). An empirical examination of perceived retail crowding, emotions, and retail outcomes. The Service Industries Journal, 29(5).

Lim, P. L., Yazdanifard, R. J. G. J. o. M., \& Research, B. (2015). What internal and external factors influence impulsive buying behavior in online shopping? Global Journal of Management and Business Research. 
Madhavaram, S. R., \& Laverie, D. A. J. A. N. A. A. (2004). Exploring impulse purchasing on the internet. ACR North American Advances.

Montgomery, A. L., \& Smith, M. D. J. J. o. I. M. (2009). Prospects for Personalization on the Internet. Journal of Interactive Marketing, 23(2), 130-137.

Ouellette, J. A., \& Wood, W. (1998). Habit and intention in everyday life: The multiple processes by which past behavior predicts future behavior. J Psychological bulletin, 124(1), 54.

Ozdemir, E., \& Akcay, G. (2019). The Effect of Gender Identity on Consumers' Impulse Buying Behavior and The Moderating Role of Biological Sex. Business and Economics Research Journal, 10(5), 1109-1125.

Park, E. J., \& Forney, J. C. (2004). A comparison of impulse buying behavior and credit card use between Korean and American college students. Journal of the Korean Society of Clothing Textiles, 28(12), 1571-1582.

Petrison, L. A., Blattberg, R. C., \& Wang, P. J. J. o. D. M. (1997). Database marketing: Past, present, and future. Journal of Direct Marketing, 11(4), 109-125.

Petty, R. E., Barden, J., \& Wheeler, S. C. (2009). The Elaboration Likelihood Model of persuasion: Developing health promotions for sustained behavioral change.

Phau, I., Lo, C. C. J. J. o. F. M., \& Journal, M. A. I. (2004a). Profiling fashion innovators. Journal of Fashion Marketing and Management.

Phau, I., Lo, C. C. J. J. o. F. M., \& Journal, M. A. I. (2004b). Profiling fashion innovators. An International Journal.

Preacher, K. J., \& Hayes, A. F. (2008). Asymptotic and resampling strategies for assessing and comparing indirect effects in multiple mediator models. Behavior research methods, 40(3), 879-891.

Rawlings, D., Boldero, J., Wiseman, F. J. P., \& differences, I. (1995). The interaction of age with impulsiveness and venturesomeness in the prediction of adolescent sexual behaviour. Personality and Individual Differences, 19(1), 117-120.

Ries, E. (2011). The Lean Startup: How Today's Entrepreneurs use continuous innovation to create radically successful businesses: Currency.

Roberts, J. A., \& Jones, E. J. J. (2001). Money attitudes, credit card use, and compulsive buying among American college students. Journal of Consumer Affairs, 35(2), 213-240.

Rook, D. W. (1987). The buying impulse. Journal of Consumer Research, 14(2), 189-199.

Saleem, A. (2019, June,29). 95\% of Pakistanis use Cash on Delivery option for e-commerce transactions. Retrieved from https://www.techjuice.pk/95-of-pakistanis-use-cash-on-delivery-option-for-ecommerce-transactions/

Sekaran, U., \& Bougie, R. J. I. N. Y. (2003). Research Methods For Business, A Skill Building Approach, John Willey \& Sons.

Sharma, P., Sivakumaran, B., \& Marshall, R. J. (2010). Impulse buying and variety seeking: A trait-correlates perspective. Journal of Business Research, 63(3), 276-283.

Sheng, H., Nah, F. F.-H., \& Siau, K. (2008). An experimental study on ubiquitous commerce adoption: Impact of personalization and privacy concerns. 9(6), 15.

Stern, H. (1962). The significance of impulse buying today. Journal of Marketing, 26(2), 59-62.

Szymanski, D. M., \& Hise, R. T. (2000). E-satisfaction: an initial examination. Journal of Retailing, 76(3), 309322.

Toch, E., Wang, Y., \& Cranor, L. F. (2012). Personalization and privacy: a survey of privacy risks and remedies in personalization-based systems. Journal of User Modeling User-Adapted Interaction, 22(1-2), 203220.

Tran, T. P. (2017). Personalized ads on Facebook: An effective marketing tool for online marketers. Journal of Retailing and Consumer Services, 39, 230-242.

Unni, R., \& Harmon, R. (2007). Perceived effectiveness of push vs. pull mobile location based advertising. Journal of Interactive Advertising, 7(2), 28-40.

Verhagen, T., \& van Dolen, W. (2011). The influence of online store beliefs on consumer online impulse buying: A model and empirical application. Information \& Management, 48(8), 320-327. 
Wells, J. D., Parboteeah, V., \& Valacich, J. S. (2011). Online impulse buying: understanding the interplay between consumer impulsiveness and website quality. Journal of the Association for Information Systems, 12(1), 3.

Westin, A. F. J. P., \& Personnel Records, T. C. L. R. . (1967). Privacy and freedom New York Atheneum.

Weun, S., Jones, M. A., \& Beatty, S. E. (1998). Development and validation of the impulse buying tendency scale. Psychological Reports, 82(3_suppl), 1123-1133.

Wu, L. (2016). Understanding the impact of media engagement on the perceived value and acceptance of advertising within mobile social networks. Journal of Interactive Advertising, 16(1), 59-73.

Xia, L., \& Bechwati, N. N. (2008). Word of mouth: the role of cognitive personalization in online consumer reviews. Journal of Interactive Advertising, 9(1), 3-13.

Xu, H., Oh, L.-B., \& Teo, H.-H. (2009). Perceived effectiveness of text vs. multimedia location-based advertising messaging. International Journal of Mobile Communications, 7(2), 154-177. 